Special Section: The economies, ecologies and politics of social forestry in Indonesia Policy Forum

\title{
Focusing on facilitation: Issues and challenges of capacity development in Indonesia's social forestry reforms
}

\author{
Gamma Galudra ${ }^{1, *}$ \\ 1 RECOFTC Indonesia Country Program \\ * Corresponding author: gamma.galudra@recoftc.org
}

\begin{abstract}
As the Indonesian government sets a target to allocate 12.7 million ha of state forest land for social forestry in 2019, one of the most crucial [and overlooked] issues is the extent of capacity, knowledge, skills, and engagement of social forestry facilitators and the extension workers that support the government in meeting their targets on social forestry. In this short paper, I seek to reorient the discussion towards the main issues and challenges of social forestry capacity development in Indonesia. On the one hand, there are some promising achievements made by the government in the wake of social forestry policy design and implementation, particularly in their ability to expand the scope of targeted areas for social forestry designation, as well as the increase in the numbers of community business group established. On the other hand, however, there are some challenges that are evident. Coordination within the ministry remains a major barrier, and extends to coordination problems across and between subnational governments. Furthermore, engagement with the private sectors and involvement of NGOs remains lacking. And finally, the distribution of social forestry facilitators and extension workers across the numerous social forestry sites in Indonesia, as well as the overall capacity development needs among facilitators continues to be a major hindrance in meeting targets. I conclude by highlighting that more attention needs to be devoted to the role and capacity of facilitators, and furthermore, that the government needs to address these challenges through various institutional reforms and methods on social forestry training, as well as developing more rigorous training modules for community facilitators.
\end{abstract}

Keywords: biodiversity; conservation planning; indigenous peoples; policy

\section{Introduction}

Indonesia's National Medium-Term Development Plan (RPJM) 2015 - 2019 set targets for social forestry (SF) to reach 12.7 million ha in 2019. Based on Ministry of Environment and Forestry (MOEF) Regulation No 83/2016, this achievement is to be met through five different schemes: Community Plantation Forests (HTR), Community Forestry (HKm), Village Forests (HD), Customary Forests (HA), and Community Forests (HR). These SF programs are also envisioned to help achieve key national development targets and priorities, whereby rural communities across Indonesia will be able to more actively engage in, and benefit from managing Indonesia's forests. This would be done through support by the government, the private sector, and NGOs. The assumption is that by bringing communities together as partners in forest governance, the result will help to achieve forest equity and sustainability in the long run.

The key to the successful implementation and achievement of SF programs and goals are contingent upon capacity development and extension services. Despite many NGOs and government officers increasingly involved in assisting forest communities, the capacity to assist SF application in Indonesia is currently considered extremely weak, in terms of policy formulation, institutional support, knowledge base, and transfer of skills.

Aware of these shortcomings on facilitation, the Directorate General Social Forestry and 
Environment Partnership passed a new decree ${ }^{1}$ on Guidance for Social Forestry Facilitation. The decree lays out to SF facilitators various approaches and guidelines on SF monitoring and evaluation, conflict resolution, setting up forest farmer groups (FFG), and entrepreneurship development. However, this policy has some flaws and neglects some important issues that need to be addressed. First, it does not discuss the strategy to improve the capacities and skills of SF facilitators and extension workers. Second, the guidance is overwhelmingly focused on achieving successful SF permits, without any guidance on how SF facilitators and extension workers can support capacity and skills development at SF sites. This highlights the key role of facilitation. Before an SF permit is signed, there are important functions that must first be adequately supported, such as planning, forest inventory, and gazettement. Third, the policy also does not explain how central and provincial governments, private companies, and NGOs can work together to facilitate communities to independently manage forests as part of SF programs.

Based on these considerations, this paper discusses how government efforts can increase and improve the capacity of SF facilitators and extension workers in Indonesia. The ambitious target to establish 12.7 million ha of social forestry certainly requires robust facilitation and extension work as a way to partner with forest communities, and creates a huge demand for the appropriate skills and knowledge base to be developed among SF facilitators and extension workers.

\section{The achievement and challenges of facilitating SF implementation in Indonesia}

There are three objectives of SF programs, (1) to develop and accelerate equal access and forest asset distribution; (2) to resolve tenurial conflict in state forests; and (3) to reduce poverty and improve community welfare in and around state forests. Overall, therefore, the main objective of SF is that forest communities can independently and sustainably manage the forest, while also enhancing their livelihoods. So far, the government has identified around 2,647 forest business groups that need to be facilitated to improve their knowledge and skills. In this section, I discuss three issues related to government efforts on establishing social forestry facilitation. These are regulations, SF facilitator personnel, and training modules and methods to improve the quality of SF facilitation. This section also discusses the challenges and difficulties for each issue.

\subsection{Regulations related to SF facilitation}

The government has developed several rules to support SF facilitation. These rules mainly regulate the activities that require facilitations, mapping FFG to determine the form of facilitation interventions and types of knowledge and skills needed for FFGs, competency standards for extension workers and facilitators in SF, materials and methods for extension workers, and guidance for development, monitoring and evaluation for SF. The government builds SiNAV, a navigation platform based on a website that helps to integrate different institutions to work and support SF programs and direct policy and facilitation for supporting SF programs. SiNAV is also used as a platform to monitor and evaluate the progress of SF based on four indicators: 1) SF access and permits application, 2) development of SF entrepreneurship, 3) tenure conflict management, and 4) increasing environmental behavior. However, I have found two challenges in these regulations, including: 1) standardizing the competency of SF facilitators through formal mechanisms limits the number of people who may potentially become SF facilitators, especially from non-government officials, and 2) despite that SiNAV is used as a platform for different government institutions and other stakeholders to work together in SF, not all stakeholders are aware about this system, especially at the provincial and district level.

\footnotetext{
${ }^{1}$ No. P.1/PSKL/KELING/KUM.1/2019
} 


\subsection{Personnel of SF facilitators}

The government has identified 3,035 extension workers, 1,215 SF facilitators, and 305 micro and small financing advisors that could support SF facilitation. As the government targets to have one facilitator for each social forestry permit, this requires numerous SF facilitators and might need more personnel and expertise beyond extension workers. The government has established SIMPING, a platform to monitor the distribution of SF facilitators and their performance. Through SIMPING, the government identified that the distribution of extension workers is unequal and not all extension workers can be used for SF programs. The government thereafter set up Social Forestry Working Groups (SFWG) at the provincial level that consists of different stakeholders (government institutions, private companies and NGOs). This group is intended to coordinate and facilitate different stakeholders who have the resources to support SF programs at the provincial level. This group is part of the recruitment mechanism from different stakeholders to support SF facilitation. Nevertheless, the process has some flaws. First, SFWG requires support from the provincial government, as the funding for its activities are expected to be allocated from the provincial government. Unfortunately, not all provincial governments support SFWG and have not followed up with adequate budget support. Many stakeholders outside of government officers, such NGOs and independent facilitators at the provincial level, are reluctant to become SF facilitators as no incentive has been provided by the government. Second, despite that SFWG has received a mandate from the provincial government to support SF programs, it has no power to enforce different stakeholders to plan and work together in the SF facilitation process. Third, the database of SIMPING should also track and identify the distribution of potential SF facilitators from government staff outside of MOEF, such as those in the Ministry of Village, Disadvantaged Development and Transmigration, as well as potential facilitators among non-government staffs that can come from private companies and NGOs. This will enable the government to identify these stakeholders and could be potentially recruited as SF facilitators from beyond the bureaucracy. This will enable the government to synergize all human resources from different stakeholders to support SF facilitation and train their capacities and skills.

\subsection{Modules and methods}

The government has published 5 modules for SF facilitators. These modules include assistance for applying for SF permits, establishing and strengthening FFGs, conflict management over forest resources, developing community forest business plans, and community forest entrepreneurship assistance. Reviewing the manuals highlights that it supports the government targets to develop forest communities as entrepreneurs. The modules were introduced alongside training of government staffs through the Regional Forest Education and Training Center in Makassar. Thereafter, the manual is planned to be introduced to other regions, including Pematang Siantar, Bogor, Pekanbaru, Kadipaten, Kupang and Samarinda. Furthermore, the government, through the Center of Forestry Education and Training at MOEF has also developed an e-learning platform for SF. The objective of this e-learning approach is to improve the ability of independent learning by participants and improve the quality of materials so that it can be easily absorbed by participants. It is planned that e-learning becomes the first phase of teaching and training facilitators about SF before being trained through classrooms system.

It is quite clear that e-learning is a supplemental method to improving the capacities of SF facilitators. Nevertheless, there are some problems in this mechanism: 1) these manuals are critiqued for not involving government staff from the MOEF Directorate General of Social Forestry and Environment Partnership (PSKL). This is important because PSKL is responsible for administering SF permits. On the other hand, PSKL has mandated that SF capacity building take place within the Directorate of Environmental Partnership; 2) the modules are considered only as a guidance manual rather than set modules, as they are not compiled and written such that the 
readers can understand and learn the materials by themselves. The modules are also written in ways that introduce the topics in a broad scope without the comprehensiveness and detail required for field applications. Each of the modules mention Participatory Rural Appraisal (PRA) with a brief explanation, but the question is whether or not all readers know how to do PRA in the field; and 3) the government does not have the data and information regarding the competencies of extensions workers and SF facilitators to support SF. This data is needed to ensure that level of knowledge matches with the trainings, and considerations about what future development should be given to the extension workers and facilitators. SIMPING provides the data and information on the skill and capacities of forest communities groups, and furthermore, to be useful SIMPING should provide this type of data on extension workers and SF facilitators. This data will also help to ensure the type of knowledge and training that needs to continue to be developed for extension workers and facilitators.

\section{Concluding Remarks}

The government is quite aware of the importance of SF facilitation when they initially set out the ambitious targets of expanding SF area, and transforming forest communities into forest entrepreneurs. The government designed several regulations, mechanism of SF facilitator recruitment, and methods and manuals for training that could support SF implementation. Nevertheless, I have described some difficulties in meeting the overall objectives, indicative of the lack of support from the provincial and district government, as well as low involvement among private companies, weak coordination between across different institutions within MOEF, lack of personnel for SF facilitations, and the lack of appreciation on extension workers and SF facilitator competencies. The government therefore, needs to develop a policy that guides all different stakeholders to support various aspects of SF facilitations, including a more flexible recruitment process that could ensure different stakeholders (e.g. NGOs and private company staff) to serve as SF facilitators, as well as support for methods and modules that combine e-learning, classroom engagement, and field applications.

\section{Acknowledgments}

The short paper is written based on the presentations and discussions of a National Workshop on 'Forest tenure reform for inclusive and equitable development: learning from experiences for a better future' convened on 22 November 2018 in Jakarta and a National Workshop on 'Strengthening the capacity of social forestry facilitators' on 18 January 2019, also in Jakarta. Both workshops were hosted by RECOFTC and AWG-SF as part of the project entitled the ASEAN-Swiss Partnership on Social Forestry and Climate Change (ASFCC), funded by the Swiss Agency for Development and Cooperation (SDC).

\section{References}

Badan Pusat Statistik. (2017). Penghitungan dan Analisis Kemiskinan Makro Indonesia Tahun 2017. Jakarta, Indonesia

World Bank. (2014). Indonesia: avoiding the trap. Jakarta: the World Bank Office 